\title{
PELUANG HUBUNGAN KARAKTERISTIK MAHASISWA BARU DENGAN MOTIVASINYA MASUK ILMU KOMPUTER
}

\author{
Syarif Hidayatullah 1), Muhamad Saad Nurul Ishlah') \\ 1)Program Studi IImu Komputer, FMIPA, Universitas Pakuan, Bogor, Indonesia \\ 2)Program Studi Sistem Informasi, Sekolah Vokasi, Universitas Pakuan, Bogor, Indonesia \\ Corresponding Author: syarif.hidayatullah@unpak.ac.id
}

\begin{abstract}
Abstrak
Terdapat berbagai faktor motivasi yang dapat mempengaruhi calon mahasiswa baru Universitas Pakuan (Unpak) dalam memilih Program Studi IImu Komputer (Prodi Ilkom) sebagai jurusan pilihannya. Agar dapat bersaing menjadi lebih baik dan berkualitas, Unpak diharapkan mampu meningkatkan pelayanannya yang prima, sehingga kebutuhan dan keinginan mahasiswa baru ketika memutuskan untuk bergabung dengan Prodi Ilkom dapat terpenuhi. Untuk itu Unpak, khususnya Prodi Ilkom perlu mengetahui hal-hal yang dibutuhkan dan diinginkan mahasiswa agar dapat bersaing. Dalam penelitian ini dilakukan survey terhadap mahasiswa baru Prodi Ilkom mengenai motivasinya bergabung dengan Prodi Ilkom untuk mengetahui apa yang diinginkan mahasiswa baru ketika memutuskan untuk bergabung. Selanjutnya berdasarkan survey yang dilakukan, digunakan metode Chi Square dan metode Bayes untuk mendapatkan peluang dari hubungan antara karakteristik mahasiswa baru dengan motivasinya masuk perguruan tinggi ketika memilih Prodi Ilkom Unpak. Hasil yang diperoleh memperlihatkan adanya hubungan signifikan antara karakteristik mahasiswa baru dengan motivasi, yang tampak dari Jenis Kelamin, Asal Daerah, Tahu Ilkom dan Media Ilkom termasuk yang digabungkan dengan kategorinya tersebut, kecuali Jenis Kelamin. Diketahui pula bahwa peluang terbesarnya terjadi pada karakteristik mahasiswa baru terhadap motivasinya, yaitu sebesar 1;0,806;0,750 dan 0,742.
\end{abstract}

Kata kunci: mahasiswa baru, motivasi, metode Chi-Square, peluang, metode bayes

\begin{abstract}
Various motivational factors can influence prospective new students at Pakuan University (Unpak) when choosing a Computer Science Department as their majors. In order to be able to compete for better quality, Unpak is expected to be able to improve its excellent service, so that the needs and desires of the new students when deciding to join the Computer Science Department can be fulfilled. In this study, a survey of new students from the Department of Computer Science about their motivation to join the Department is conducted to find out what new students want when they decide to join. Furthermore, based on the survey, the Chi-Square method and Bayes method are used to get the probability of the relationship between the characteristics of new students and their motivation to go to the College when choosing the Department. The results show that there is a significant relationship between the characteristics of new students with motivation, which can be seen from the Gender, Regional Origin, Previous Information about Computer Science program and Computer Science Program Media including those that are combined in the above categories, except for Gender. It shows the greatest opportunity occurred in the characteristics of new students to the motivation of $1 ; 0.806 ; 0.750$ and 0.742 .
\end{abstract}

Keywords: new students, motivation, Chi-Square method, opportunities, bayes method

\section{Pendahuluan}

Menurut catatan Pusat Informasi Akademik (Putik) Universitas Pakuan pada tahun 2019, dari 3463 mahasiswa baru yang terdaftar di Universitas Pakuan, terdapat sebanyak 241 mahasiswa yang memilih Program Studi IImu Komputer (Prodi Ilkom). Semakin banyak mahasiswa baru yang masuk Program Studi Ilkom, menjadikan Universitas Pakuan harus 
meningkatkan pelayanannya yang prima agar bisa tetap bersaing menjadi lebih baik dan berkualitas, sehingga kebutuhan dan keinginan mahasiswa baru dapat terpenuhi. Untuk itu Universitas Pakuan, khususnya Prodi Ilkom perlu mengetahui hal-hal yang dibutuhkan dan diinginkan mahasiswa agar dapat bersaing.

Di antara berbagai faktor yang diperkirakan dapat mempengaruhi motivasi untuk masuk perguruan tinggi, khususnya memilih Program Studi yang menjadi pilihannya, adalah adanya anggapan bahwa dengan kuliah itu akan menjadi lebih keren/hebat, dapat membantu mendapatkan pekerjaan dengan mudah, menambah ilmu bermanfaat untuk bekal di masa depan, membahagiakan orang tua dan sebagainya. Hasil penelitian [17] menunjukkan bahwa untuk mengidentifikasi karakteristik motivasi belajar mahasiswa untuk mengetahui keberhasilan belajarnya, dapat dilandasi beberapa faktor, yaitu: usia, jenis kelamin dan perbedaan tempat tinggal dengan orang tua atau tidak.

Metode Statistika yang dibutuhkan untuk masalah ini adalah melalui pendekatan yang dapat menunjukkan variabel-variabel bebas yang memiliki derajat hubungan atau pengaruh kuat terhadap variabel terikat, dan mengidentifikasi karakteristik mahasiswa baru yang paling berbeda menurut variabel-variabel tersebut. Salah satunya adalah metode yang dipakai dalam analisis dependensi, yaitu metode Chi-Square [6], [14]. Selain itu, untuk mendapatkan seberapa besar peluang yang didapat berdasarkan karakteristik terhadap motivasinya dan peluang yang didapat dari motivasi terhadap karakteristiknya ini akan digunakan metode Bayes [1], [6], [14], [16]. Tujuannya adalah untuk menemukan hubungan antara karakteritik mahasiswa baru dengan motivasinya[13]. Serta seberapa besar peluang dari karakteristik itu terhadap motivasinya termasuk sebaliknya.

Pada penelitian ini, objek penelitian dibatasi pada mahasiswa Prodi Ilkom Universitas Pakuan. Data yang digunakan merupakan data yang diperoleh melalui pengisian kuesioner yang disebarkan kepada mahasiswa secara langsung.

\section{Metode Penelitian}

Metode yang digunakan pada penelitian ini dimulai dengan mempersiapkan populasi dan sampel, kemudian berdasarkan populasi dan sampel tersebut dilakukan pengambilan data melalui kuisioner, dan terakhir setelah data kuisioner terkumpul, dilakukan pengolahan data dengan melakukan beberapa tes uji.

\subsection{Populasi dan Sampel}

Untuk keperluan penelitian ini digunakan populasi dari mahasiswa sebanyak 241 mahasiswa baru yang memilih yang Program Studi IImu Komputer. Sedangkan yang digunakan sebagai sampel adalah sebanyak 150 mahasiswa. Dalam hal ini digunakan Metode Solvin $[3,16]$ untuk menentukan banyaknya sampel yang digunakan dalam penelitian ini.

Rumus Solvin:

Keterangan :

$$
n=\frac{N}{1+N e^{2}}
$$

$\mathrm{n}=$ banyak sampel

$\mathrm{N}=$ banyak populasi

$\mathrm{e}=$ tingkat kesalahan

Hasil perhitungan banyak sampel dalam penelitian ini adalah:

\subsection{Kuesioner}

$$
\begin{aligned}
n & =\frac{241}{1+241(0,05)^{2}}=150,39 \\
& \cong 150 \text { mahasiswa }
\end{aligned}
$$

Dalam penelitian ini peneliti menggunakan kuesioner [1] untuk mencari hubungan antara karakteristik mahasiswa baru dengan motivasinya. Kuesioner dengan sejumlah pertanyaanpertanyaan tertulis yang digunakan untuk memperoleh informasi dari responden dalam hal ini mahasiswa baru adalah tentang karakteritik dan motivisainya. 


\subsection{Pengolahan data}

Data penelitian itu kemudian diolah, diawali dengan uji validitas dan uji reliabilitas $[3,16]$ untuk mendapatkan tingkat validitas dan reliabilitas. Kemudian dilakukan uji Chi Square untuk mendapatkan tingkat kesignifikanan dari hubungan antara dua variabel terakhir. Selanjutnya, untuk mendapatkan besar peluang bersyarat digunakan metode Bayes.

\section{Hasil dan Pembahasan}

3.1 Analisis Univariat

Analisis Univariat $[8,9,15]$ digunakan untuk menganalisis karakteristik mahasiswa baru dengan motivasi masuk Program Studi IImu Komputer di Perguruan Tinggi Unpak diberikan dalam Tabel 2.

Tabel 1. Karakteristik Mahasiswa baru dengan motivasi masuk Program Studi Ilmu Komputer

\begin{tabular}{llll}
\hline No & Karakteristik & N & $\%$ \\
\hline 1 & Jenis Kelamin & 128 & 81,3 \\
& 1. Laki-laki & 28 & 18,7
\end{tabular}

2 Usia

$\begin{array}{lll}\text { 1. Usia }<18 \text { tahun } & 13 & 8,7 \\ \text { 2. Usia } 18-20 \text { tahun } & 134 & 89,3 \\ \text { 3. Usia } 21-23 \text { tahun } & 2 & 1,3 \\ \text { 4. Usia }>23 \text { tahun } & 1 & 0,7\end{array}$

3 Pendidikan

1. SMA/MA - IPA $66 \quad 44,0$

2. SMA/MA - IPS $\quad 20 \quad 13,3$

3. SMK-IPA $50 \quad 33,4$

4. SMK-IPA $11 \quad 7,3$

5. Lain-lain 32,0

$4 \quad$ Asal daerah

1. Kota Bogor $48 \quad 32,0$

2. Kabupaten Bogor $68 \quad 45,3$

3. Diluar Bogor $34 \quad 22,7$

5 Tempat Tinggal

1. Rumah orang tua $\quad 126 \quad 84,0$

2. Rumah saudara $\quad 6 \quad 4,0$

3. Indekos/Kos $13 \quad 8,7$

4. Kontrak 2 1,3

5. Lain-lain 32,0

6 Berangkat menuju kampus menggunakan

1. Jalan kaki $12 \quad 8,0$

2. Naik angkot $20 \quad 13,3$

3. Naik motor sendiri $\quad 98 \quad 65,4$

4. Naik motor ojol $\quad 8 \quad 5,3$

5. Naik mobil sendiri $\quad 1 \quad 0,7$

6. Lain-lain $\quad 11 \quad 7,3$

7 Tahu llkom dari

1. Diri sendiri $42 \quad 28,0$

$\begin{array}{lll}\text { 2. Teman } & 42 & 28,0\end{array}$ 
3. Orang tua $30 \quad 20,0$

4. Saudara $28 \quad 18,7$

5. Orang lain $\quad 8 \quad 5,3$

8 Media Ilkom dari

1. Internet $\quad 84 \quad 56,0$

2. Koran $\quad 4 \quad 2,7$

3. Brosur $\quad 37 \quad 24,6$

4. Pamflet 32,0

5. Lain-lain $22 \quad 14,7$

$9 \quad$ Tingkat pengaruh terhadap motivasi

masuk program studi ilmu komputer

1. Tidak pengaruh

3,3

\subsection{Peluang hubungan antara variabel}

Variabel motivasi dan variabel karakteristik mahasiswa baru yang masuk prodi ilkom adapun kategori motivasi meliputi:

$$
\begin{aligned}
& M 1=\text { Keren/Hebat } \\
& M 2=\text { Kerja } \\
& M 3=\text { Ilmu } \\
& M 4=\text { Orang tua } \\
& M 5=\text { Lain-lain }
\end{aligned}
$$

Sedangkan variabel karakteristik mahasiswa baru ini yang signifikan meliputi : Jenis kelamin, Asal daerah, tahu ilkom dan media ilkom. Peluang Motivasi mahasiswa berkeinginan menjadi keren terhadap jenis kelamin Laki-laki berdasarkan [5] dan [6]:

$$
\begin{aligned}
P(M 1 \mid J K 1)= & \frac{P(J K 1 \mid M 1) \cdot P(J K 1)}{P(J K 1 \mid M 1) \cdot P(J K 1)+P(J K 2 \mid M 1) \cdot P(J K 2)} \\
& =\frac{1 \cdot \frac{122}{150}}{1 \cdot \frac{122}{150}+0 . \frac{122}{150}}=1 \text { atau } 100 \% .
\end{aligned}
$$

Peluang Motivasi lainnya dari mahasiswa terhadap jenis kelamin dapat dilihat pada Tabel 3:

Tabel 2. Peluang motivasi mahasiswa terhadap jenis kelamin

\begin{tabular}{ccc} 
& \multicolumn{2}{c}{ Jenis } \\
\hline Motivasi & JK1 & JK2 \\
\hline $\boldsymbol{M 1}$ & 1 & 0 \\
$\boldsymbol{M} 2$ & 0,913 & 0,087 \\
$\boldsymbol{M 3}$ & 0,962 & 0,038 \\
$\boldsymbol{M 4}$ & 0,984 & 0,016 \\
$\boldsymbol{M 5}$ & 0,859 & 0,141 \\
\hline
\end{tabular}

Kategori Jenis Kelamin meliputi:

JK1 = Laki-laki

$\mathrm{JK} 2$ = Perempuan

Peluang hubungan motivasi mahasiswa dapat Kerja lebih mudah terhadap asal daerah Kota Bogor berdasarkan [5] dan [6]:

$$
P(M 2 \mid A 1)=\frac{P(A 1 \mid M 1) \cdot P(A 1)}{P(A 1 \mid M 2) \cdot P(A 1)+P(A 2 \mid M 2) \cdot P(A 2)+P(A 3 \mid M 2) \cdot P(A 3)}
$$




$$
=\frac{\frac{10}{41} \cdot \frac{48}{150}}{\frac{10}{41} \cdot \frac{48}{150}+\frac{17}{41} \cdot \frac{68}{150}+\frac{14}{41} \cdot \frac{34}{150}}=0,227 \text { atau } 22,7 \%
$$

Peluang Motivasi lainnya dari mahasiswa baru terhadap Asal daerah dapat dilihat pada Tabel 4 berikut:

Tabel 3. Peluang mahasiswa baru berdasarkan "asal daerah"

\begin{tabular}{cccc}
\hline \multirow{2}{*}{ Motivasi } & \multicolumn{3}{c}{ Asal Daerah } \\
& A1 & A2 & A3 \\
\hline $\boldsymbol{M 1}$ & 1 & 0 & 0 \\
$\boldsymbol{M} 2$ & 0,227 & 0,547 & 0,225 \\
$\boldsymbol{M} 3$ & 0,320 & 0,536 & 0,144 \\
$\boldsymbol{M 4}$ & 0,156 & 0,771 & 0,073 \\
$\boldsymbol{M 5}$ & 0,459 & 0,433 & 0,108 \\
\hline
\end{tabular}

Kategori Asal daerah meliputi:

$$
\begin{aligned}
& \text { A1 }=\text { Kota Bogor } \\
& \text { A2 }=\text { Kabupaten Bogor } \\
& \text { A3 }=\text { Luar Bogor }
\end{aligned}
$$

Peluang Motivasi mahasiswa mendapat kan IImu terhadap tahu IImu Komputer (tahu ilkom) ada di UNPAK dari orang lain:

$$
\begin{array}{r}
P(M 3 \mid T 5)=\frac{P(T 5 \mid M 3) \cdot P(T 5)}{P(T 1 \mid M 3) \cdot P(T 1)+P(T 2 \mid M 3) \cdot P(T 2)+\cdots+P(A 5 \mid M 3) \cdot P(T 5)} \\
=\frac{\frac{1}{62} \cdot \frac{8}{150}}{\frac{20}{62} \cdot \frac{42}{150}+\frac{13}{62} \cdot \frac{42}{150}+\frac{13}{62} \cdot \frac{30}{150}+\frac{15}{62} \cdot \frac{28}{150}+\frac{1}{62} \cdot \frac{8}{150}}=0,004 \approx 0,4 \%
\end{array}
$$

Peluang Motivasi lainnya dari mahasiswa baru terhadap tahu Ilmu Komputer (tahu ilkom) ada di UNPAK seperti pada Tabel 5 berikut:

Tabel 4. Peluang motivasi mahasiswa terhadap "tahu ilkom"

\begin{tabular}{cccccc}
\hline \multirow{2}{*}{ Motivasi } & \multicolumn{5}{c}{ TAHU ILKOM } \\
\cline { 2 - 6 } & T1 & T2 & T3 & T4 & T5 \\
\hline M1 & 0,808 & 0,000 & 0,192 & 0,000 & 0,000 \\
M2 & 0,349 & 0,320 & 0,145 & 0,175 & 0,011 \\
M3 & 0,381 & 0,248 & 0,177 & 0,190 & 0,004 \\
M4 & 0,153 & 0,613 & 0,110 & 0,102 & 0,022 \\
M5 & 0,335 & 0,223 & 0,399 & 0,000 & 0,043 \\
\hline
\end{tabular}

Peluang Motivasi mahasiswa mendapatkan Kerja terhadap tahu Program Studi IImu Komputer ada di UNPAK lewat media (Media llkom) berupa Internet:

$$
\begin{aligned}
P(M 2 \mid M e 1) & =\frac{P(M e 1 \mid M 2) \cdot P(M e 1)}{P(M e 1 \mid M 2) \cdot P(T 1)+P(M e 2 \mid M 2) \cdot P(T 2)+\cdots+P(M e 5 \mid M 2) \cdot P(T 5)} \\
& =\frac{\frac{29}{41} \cdot \frac{84}{150}}{\frac{29}{41} \cdot \frac{84}{150}+\frac{1}{41} \cdot \frac{4}{150}+\frac{9}{41} \cdot \frac{37}{150}+\frac{1}{41} \cdot \frac{3}{150}+\frac{1}{41} \cdot \frac{22}{150}} \\
& =0,871 \text { atau } 87,1 \%
\end{aligned}
$$


Peluang Motivasi lainnya dari mahasiswa terhadap tahu Program Studi IImu Komputer ada di UNPAK lewat media (Media Ilkom) disajikan pada Tabel 6.

Tabel 5. Peluang motivasi mahasiswa terhadap media ilkom

\begin{tabular}{cccccc}
\hline \multirow{2}{*}{ Motivasi } & \multicolumn{5}{c}{ Media Ilkom } \\
\cline { 2 - 6 } & $M e 1$ & $M e 2$ & $M e 3$ & $M e 4$ & $M e 5$ \\
\hline M1 & 0,000 & 0,000 & 0,359 & 0,000 & 0,641 \\
M2 & 0,871 & 0,001 & 0,119 & 0,001 & 0,008 \\
M3 & 0,812 & 0,003 & 0,145 & 0,000 & 0,040 \\
M4 & 0,737 & 0,000 & 0,195 & 0,004 & 0,064 \\
M5 & 0,509 & 0,000 & 0,224 & 0,000 & 0,267 \\
\hline
\end{tabular}

\subsection{Analisis Bivariat}

Analisis bivariat [8], [9], dan [14] hubungan antara hasil penggabungan kategori variabel karakteristik mahasiswa dengan variabel motivasinya disajikan pada Tabel 7.

Tabel 6. Penggabungan kategori antarvariabel

\begin{tabular}{|c|c|c|c|c|c|c|}
\hline \multicolumn{2}{|c|}{ Karakteristik } & \multicolumn{5}{|c|}{ Motivasi } \\
\hline Kategor & & $M 1$ & M1 & M3 & M4 & M5 \\
\hline \multirow[t]{2}{*}{ Asal Daerah } & A1 & 1 & 0,244 & 0,355 & 0,194 & 0,500 \\
\hline & A2 & 0 & 0,75 & & 0,0 & \\
\hline \multirow[t]{2}{*}{ Tahu Ilkom } & T1 & 1 & 0,4 & & 0,258 & 0,667 \\
\hline & $\mathrm{T} 2$ & 0 & 0,5 & & 0,742 & 0,333 \\
\hline \multirow[t]{2}{*}{ Media Ilkom } & Me1 & 1 & 0,707 & 0,597 & 0,484 & 0,250 \\
\hline & Me2 & 0 & 0,293 & 0,403 & 0,516 & 0,750 \\
\hline
\end{tabular}

Pada variabel karakteristik Asal Daerah dengan kategori A1 : Kota Bogor, A2 : Diluar Kota Bogor meliputi (Kabupaten Bogor, Diluar Bogor), Tahu Ilkom dengan kategori T1 : Didalam keluarga meliputi (diri sendiri, orang tua), T2 : Diluar keluarga meliputi (teman, saudara ,orang lain) dan Media Ilkom dengan kategori Me1 : Internet, Me2: Non Internet meliputi (Koran, Brosur, Pamplet, lain-lain). Sedangkan variabel Motivasi dengan kategori M1 : Positif meliputi (Kerja,Ilmu,Orang tua) , M2 : Kurang Positif meliputi (Keren, lain-lain).

Hasil yang diperoleh dari analisis Chi Square dengan menggunakan tabel kontingensi diperoleh adanya hubungan antara hasil penggabungan kategori variabel karakteristik mahasiswa meliputi (Asal Daerah, Tahu Ilkom dan Media Ilkom) dengan variabel Motivasi signifikan.

Peluang terbesar terjadi pada peluang Motivasi mahasiswa baru dengan kuliah menjadi keren terhadap karakteristik asal daerah, tahu ilkom dan media ilkom dengan kategori dari kota Bogor, dalam keluarga dan media internet sebesar 1 atau $100 \%$ dan peluang terkecil terjadi pada peluang Motivasi mahasiswa dengan kuliah jadi keren yang lewat media selain internet meliputi koran, brosur, pamflet atau lainnya sebesar $0 \%$.

Sedangkan Peluang terbesar dan terkecil lainnya pada Motivasi dengan kuliah menjadi keren adalah sebagai berikut :

a. Peluang terbesar terjadi pada peluang Motivasi mahasiswa baru karena ingin membahagiakan orang tua terhadap karakteristik mahasiswa asal daerah diluar kota Bogor sebesar 0,806 atau $80,6 \%$ dan peluang terkecil terjadi pada peluang Motivasi mahasiswa baru karena ingin membahagiakan orang tua terhadap karakteristik mahasiswa asal daerah kota Bogor sebesar 0,194 atau 19,4\%. 
b. Peluang terbesar terjadi pada peluang Motivasi mahasiswa baru karena ingin membahagiakan orang tua terhadap karakteristik mahasiswa tahu ilkom diluar keluarga sebesar 0,742 atau $74,2 \%$ dan peluang terkecil terjadi pada peluang Motivasi mahasiswa baru karena ingin membahagiakan orang tua terhadap karakteristik mahasiswa tahu ilkom didalam keluarga sebesar 0,258 atau 25,8\%.

c. Peluang terbesar terjadi pada peluang Motivasi mahasiswa baru yang lainnya terhadap karakteristik mahasiswa baru yang tahu ilkom dari media non internet sebesar 0,750 atau 75,0 $\%$ dan peluang terkecil terjadi pada peluang Motivasi mahasiswa baru yang lainnya terhadap karakteristik mahasiswa baru yang tahu ilkom dari media internet sebesar 0,250 atau 25,0 \%.

\section{Kesimpulan}

Berdasarkan hasil analisis metode Chi-Square dan Metode Bayes tentang hubungan karakteristik mahasiswa baru terhadap motivasinya masuk IImu Komputer UNPAK dapat disimpulkan bahwa, hubungan antara karakteristik mahasiswa baru dengan motivasinya untuk masuk IImu Komputer Unpak dengan karakteristik Asal daerah, Tahu Ilkom dan Media Ilkom berpengaruh secara signifikan. Peluang terbesar terjadi pada Motivasi mahasiswa baru "dengan kuliah menjadi keren" terhadap karakteristik asal daerah, tahu ilkom dan media ilkom dengan kategori dari kota Bogor, dalam keluarga dan media internet sebesar 1 atau $100 \%$.

Peluang terbesar lainnya, yaitu Motivasi mahasiswa baru karena ingin membahagiakan orang tua terhadap karakteristik mahasiswa asal daerah di luar kota Bogor, lainnya terhadap karakteristik mahasiswa baru yang tahu ilkom dari media non internet dan karena ingin membahagiakan orang tua terhadap karakteristik mahasiswa tahu ilkom di luar keluarga sebesar 0,$806 ; 0,750$ dan 0,742 . Peluang terkecil terjadi pada peluang Motivasi mahasiswa baru karena ingin membahagiakan orang tua terhadap karakteristik mahasiswa tahu ilkom di dalam keluarga, yang lainnya terhadap karakteristik mahasiswa baru dari media ilkom internet, karena ingin membahagia kan orang tua terhadap karakteristik mahasiswa asal daerah kota Bogor dan sebesar 0,258;0,250 dan 0,194. Peluang terkecil sekali terjadi pada peluang Motivasi mahasiswa baru dengan kuliah jadi keren terhadap media ilkom non internet sebesar 0 .

Beberapa saran yang dapat diberikan untuk penelitian selanjutnya adalah metode ini dapat digunakan untuk kasus lainnya yang memiliki masalah lebih kompleks. Selain itu, dapat gunakan pula metode lain selain metode Chi-Square dan Metode Bayes untuk kasus seperti ini sehingga diperoleh yang diharapkan.

\section{Referensi}

[1] Singarimbun, Masri. Metode Penelitian dan Survei. Jakarta: LP3S, 1989.

[2] Ronald E. Walpole, Raymond H. Myers. IImu Peluang dan Statistika untuk Insinyur dan Ilmuwan, Bandung: Penerbit ITB, 1986.

[3] Syofian Siregar. Metode Penelitian Kuantitatif Dilengkapi dengan Perbandingan Perhitungan Manual dan SPSS, Jakarta: Kencana Prenada Media Group, 2013.

[4] Ni Luh Putu Emayanti, Dewa Ayu Puspawati, Deden Ismail. 2015. Pembelajaran Berbasis ECO-TAS dengan Model Piknik Metafora untuk Menganalisis Pengetahuan Konseptual dan Prosedural Siswa Melalui Media Cycle Mapping. Jurnal Bakti Saraswati, vol. 4.

[5] Rita Hamdani. 2016. Penerapan Metode Bayes dalam Mendiagnosa Gangguan Perkembangan pada Anak. Jurnal Mantik Penusa, vol. 20: hal. 70.

[6] Sari Murni, Fristi Riandari. 2018. Penerapan Metode Teorema Bayes Pada Sistem Pakar Untuk Mendiagnosa Penyakit Lambung. Jurnal Jutikomp. Vol. 1: hal. 21.

[7] Nur Fitria Rochmawati, Wahyu Hidayat Riyanto, Ida Nuraini. 2018. Hubungan Tingkat Pendidikan, Usia, dan Pengalaman Kerja Terhadap Pendapatan Pekerja Wanita pada Industri Kerajinan Dompet Ida Collection di Desa Pulo Kecamatan Tempeh Kabupaten Lumajang. Jurnal IImu Ekonomi. Vol. 2: hal. 399-408. 
[8] Wita Solama, Aulia Hati Apisah. 2019. Kejadian Dismenore Primer pada Siswi SMK Berdasarkan Usia Menarche, Indeks Masa Tubuh dan Siklus Menstruasi. Jurnal IImiah Multi Science Kesehatan. Vol. 11: hal. 112-113.

[9] Made Wahyu Krisnandewi, I Wayan Gede Sutadarma, Desak Made Wihandani. 2019 Hubungan Jumlah Konsumsi Jeruk terhadap Kejadian Batu Ginjal di RSUP Sanglah Denpasar. Jurnal Intisari Sains Medis. Vol. 10, No. 3: hal. 730-736.

[10] R. P. Erwin. Teknik Bayesian Network pada Pengolahan Citra untuk Identifikasi. in Prosiding Seminar Nasional Penelitian dan PKM Sains, Teknologi dan Kesehatan. Palembang, 2014.

[11] Astrid Novita Putri, Siti Asmiatun, Nur Wakhidah. Klasifikasi Kondisi Permukaan Jalan menggunakan Algoritma Naive Bayes. in Prosiding Seminar Nasional PPM Universitas Surabaya, Surabaya, 2018.

[12] Sara Novi Pinor, B. H. Ralph Kairupan, Sefti Rompas. 2018. Hubungan antara Locus of Control dan Emotional Quotient(EQ) dengan Kelelahan Kerja Perawat di RS Bhayangkara TK.III Manado. Jurnal Keperawatan. Vol. 6.

[13] Andriani, E. N., Saepulrohman, A., \& Apriliya, S. 2016. The development of children's story book about Acep Zamzam Noor to support learning bahasa Indonesia in elementary school. Man in India, 96(12), 4931-4945.

[14] V. S. Fadhilla Chrisanti. Hubungan Konsumsi Susu dengan Usia Menarche pada Anak Usia 12-15 Tahun in Prosiding Seminar Nasional PPM Universitas Surabaya. Surabaya. 2018.

[15] Ayu Andini. 2018. Tingkat Pengetahuan Mahasiswa Di empat Fakultas Kesehatan Universitas Sumatera Utara tentang Penyakit Kanker Payudara. (Skripsi). Prodi Farmasi Fakultas Farmasi USU. Medan.

[16] Hidayatullah S. Statistika Farmasi dilengkapi perhitungan Statistik Excel dan SPSS, Yogyakarta: Innosain Graha IImu, 2018.

[17] Setiadi C. Y., Kurniawati A., Soesanto R. P. 2014. Analisis Karakteristik Motivasi Belajar Mahasiswa Fakultas Rekayasa Industri Angkatan 2013 Telkom University Menggunakan Knowledge Conversion 5C. Jurnal Rekayasa Sistem dan Industri. Vol 1, No.1. 